\title{
Preputial Hematoma in a 2 Years Old Horse
}

\author{
Funcia JP*, Goñi JI and Guglielminetti A
}

Centro de rehabilitación y Hospital equino Kawell, Solís, Provincia de Buenos Aires, Argentina

\begin{abstract}
A 2 years old Polo Horse was admitted with a severe swelling of the prepuce and paraphimosis. Paraphimosis occurs most frequently from preputial edema. In stallions is an emergency demanding immediate, aggressive medical treatment. The owners and the veterinarian suspected of an acute trauma. Immediate diagnosis of preputial hematoma was performed by ultrasonography. The ultrasonography at the clinical examination allows us to differentiate conditions to select the appropriate treatment. A successful treatment is totally related to reduce edema. This report describes the history, clinical findings, management and progression of a preputial hematoma with paraphimosis in a 2 year old Polo horse.
\end{abstract}

Keywords: Stallion; Preputial; Hematoma; Equine; Treatment

\section{Introduction}

Acute injury to the penis or prepuce may result from trauma during breeding, sedative induced (phenothiazine tranquilizers), undesirable interactions with environmental obstacles or inadvertently during urogenital surgery [1]. Preputial swelling may arise from local inflammation, neoplasms or systemic disease characterized by extensive edema [2], subsequent to acute hemorrhage [3], preputial hernia [4], habronemiasis [5], preputial abscess [2], dourine (Trypanosoma equiperdum) and purpura hemorrhagic [6]. Penile and preputial injury or prolonged prolapsed of the penis leads to the rapid development of edema, usually within 6-24 h [6].

Paraphimosis, or the inability of the horse to retract its protruded penis into the prepuce, occurs most frequently from preputial edema [2]. In stallions is an emergency demanding immediate, aggressive medical treatment [7].

Immediate diagnosis of preputial hematoma can be asses by ultrasonography.

Failure to treat paraphimosis can have catastrophic consequences for a breeding stallion [7]. This report describes the history, clinical findings, management and progression of a preputial hematoma with paraphimosis in a 2 year old Polo horse.

\section{Case Report}

\section{History}

A 2 years old Polo Horse was admitted to Centro de rehabilitación y Hospital equino Kawell with a severe swelling of the prepuce and paraphimosis. The owners and the veterinarian suspected of an acute trauma, because skin lacerations in proximal metatarsus of both hind limbs were observed. The horse has received Phosphate Dexamethasone $(0.1 \mathrm{mg} / \mathrm{kg}$; IV) and Flunixine meglumine $(1.1 \mathrm{mg} / \mathrm{kg} ; \mathrm{IV})$ before presentation at the hospital.

\section{Clinical examination}

Upon admission, the horse underwent routine clinical examinations. The horse had normal appetite. Rectal temperature was $38.5^{\circ} \mathrm{C}$; heart rate and respiratory rate were 64 beats/minute and 16 breaths/minute, respectively. The mucous membrane and capillary refill time were normal.

The examination revealed prolapsed prepuce (Figure 1). The

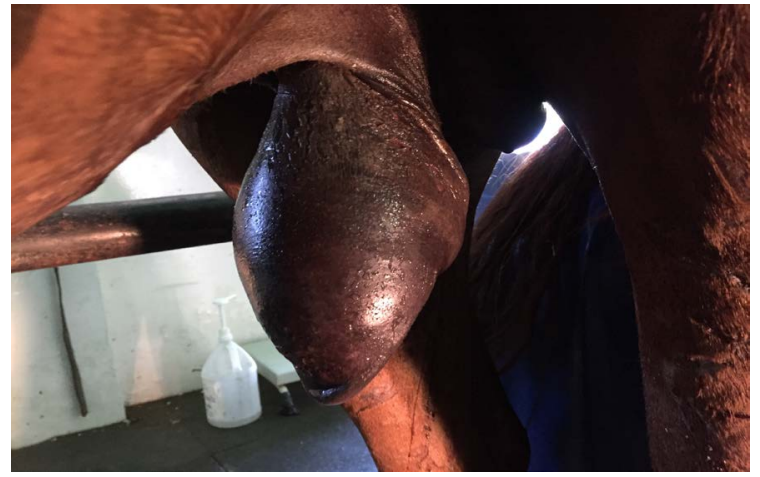

Figure 1: Severe swelling and prolapsed of the prepuce at the admission.

swelling of the prolapsed portion of the prepuce was no painful upon manipulation. The glans penis was not protruding from the preputial cavity.

Ultrasonographic examination with a $3.5 \mathrm{MHz}$ convex transducer (M-Turbo Ultrasound System; Fujifilm Sonosite Inc., WA, USA) determined severe amount of hyperechoic fluid, compatible with the characteristic of blood, between internal lamina of the external fold of the prepuce and the penis. No abnormalities in the penis were found and no communication between the hematoma and the corpus cavernosum (Figure 2).

At this stage, it was assumed a diagnosis of paraphimosis secondary to preputial hematoma result of trauma. Differentials included a prepuce infection, preputial hernia, preputial seroma, haemangiosarcoma, squamous cells carcinoma, squamous cells papilloma, lymphoma, sarcoids, habronemiasis, dourine (Trypanosoma equiperdum) and purpura hemorrhagic.

*Corresponding author: Funcia Juan Pablo, Centro de rehabilitación y Hospita equino Kawell, Km 95, 100 Ruta Nacional Numero 8, Solis (C.P. B2764), Buenos Aires, Argentina, Tel: 542-326-492-325; E-mail: juanpablo.f@centrokawell.com.ar

Received May 17, 2016; Accepted May 24, 2016; Published May 27, 2016

Citation: Funcia JP, Goñi JI, Guglielminetti A (2016) Preputial Hematoma in a 2 Years Old Horse. J Vet Sci Technol 7: 338. doi:10.4172/2157-7579.1000338

Copyright: @ 2016 Funcia JP, et al. This is an open-access article distributed under the terms of the Creative Commons Attribution License, which permits unrestricted use, distribution, and reproduction in any medium, provided the original author and source are credited. 


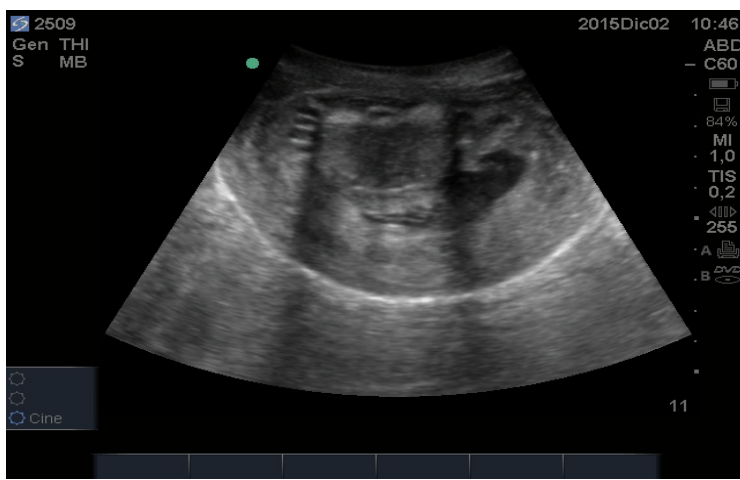

Figure 2: Ultrasound at the clinical examination.

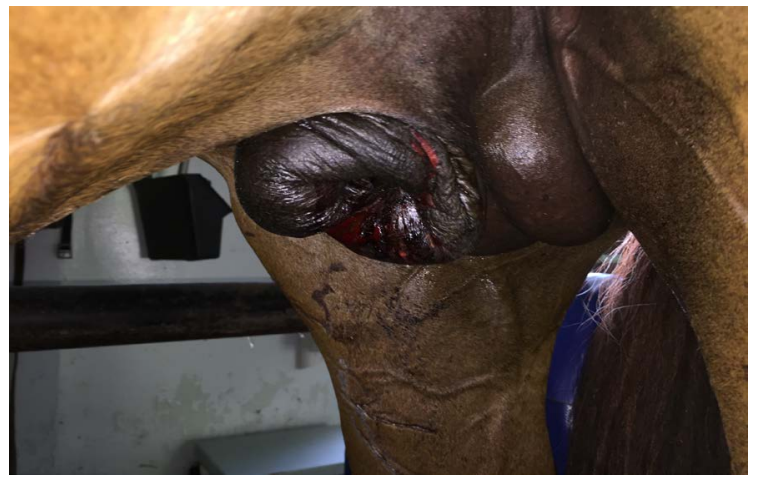

Figure 3: Six hours later of the ultrasound guided punction.

\section{Treatment}

The horse was restrained in stocks and sedated with xylazine hydrochloride (Xylazina 10\%; Pro Ser S.A., Buenos Aires, Argentina) $(0.5 \mathrm{mg} / \mathrm{kg}$; IV $)$ to facilitate the procedure. It was performed an ultrasound guided punction with a $n^{\circ} 24$ surgical blade (Printex; Kehr Surgical Private Limited, India) of the hematoma for promotes the drainage of it. Manual massage was perfomed to reduce hematoma content and flushed with $500 \mathrm{ml}$ dilute Povidone Iodine solution (Icubex 10; Laboratorio Rodriguez Vidal S.R.L, Quilmes, Buenos Aires, Argentina) $(1 \%[\mathrm{vol} / \mathrm{vol}]$ in sterile saline $[0.9 \% \mathrm{NaCl}]$ solution) (Figure 3). As daily therapy, the horse was established manual massage and hydrotherapy with cold water 15 minutes twice a day, to improve the circulation and promote the decrease of the edema. Benzalkonium chloride cream (Fortiseptin, Laboratorios Forti S.R.L. -Ciudad Autónoma de Buenos Aires, Buenos Aires, Argentina) (0.1\%) and Vaseline was applied topically to the penis and prepuce. After the admission, the stallion was treated with Penicillin and Streptomycin (Cumebiotic 6M, Laboratorios Agropharma -Moreno, Buenos Aires, Argentina) (2.700.000 UI of Sodium Penicillin, 3.300.000 UI of Procaine Penicillin and $2.5 \mathrm{~g}$ of Streptomycin, IM every 12 hours) and Gentamicin (Gentamicin 8\%, Laboratorios Equi Systems S.R.L. -Munro, Buenos Aires, Argentina) (6.6 mg/kg; IV every 24 hours) for 5 days. After treatment with Penicillin and Gentamicin, began to treat the patient with Enrofloxacin (Enrrofloxacina Ruminal, Laboratorios Ruminal S.A. -Florida, Buenos Aires, Argentina) (5 mg/kg; PO every 12 hours) for 9 days. Flunixin (Flunix Deltavet, Laboratorios Deltavet -Morón, Buenos Aires, Argentina) (1.1 mg/kg; IV every 12 hours) was administered for 3 days and continued with Oral Fenilbutazone (Fen-Oral, Laboratorios Clínica Equina - PROSER S.A. -Capitán

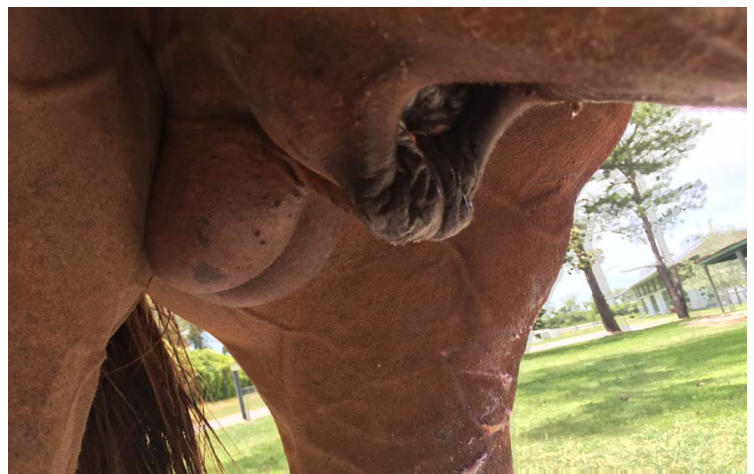

Figure 4: 14 days of treatment, the patient at discharge.

Sarmiento, Buenos Aires, Argentina) (1 g; PO every 12 hours) for the next 11 days, for the anti-inflammatory properties of NSAIDs. The first day of treatment, corticoids therapy was established with EV Dexamethasone (Dexa 40, Laboratorios Equi Systems S.R.L. -Munro, Buenos Aires, Argentina) $(0.05 \mathrm{mg} / \mathrm{kg}$; IV) owing to the fact that it has anti-inflammatory properties. Furosemide (Salix, Laboratorios Intervet Argentina S.A. -Martínez, Buenos Aires, Argentina) (0.5 $\mathrm{mg} / \mathrm{kg}$; IV every 24 hours) was used the first day of treatment and Trichlormetiazida and dexamethasone acetate (Naquasone, ScheringPlough Santé Animale -La Grindoliere, Segré, France) (100 mg/5.5 mg respectively; IM every 24 hours) for two days, as diuretic drugs, to reduce the preputial edema. From the first day of hospitalization until the patient was discharged, Oral Ranitidine (Ranitidina WK, Laboratorios Windhoek S.R.L. -Munro, Buenos Aires, Argentina.) was used $(6.6 \mathrm{mg} / \mathrm{kg}$; PO every 8 hours) as anti-ulcer drug.

During all treatment, the horse was hand-walked for 15 minutes every 4 hours to improve the edema reduction by facilitate local lymphatic and venous drainage. The eleventh day of treatment, the prepuce had mild edema. The ultrasound examination revealed a mild amount of anechoic fluid in the preputial cavity. Therefore, the prepuce was drained by $16 \mathrm{G}$-needle punction (Abbocath ${ }^{\mathrm{TM}-\mathrm{T}}$; Hospira INC, Illinois, USA), serous fluid was collected.

The evolution of the patient to treatment was favorable, and evidenced by a decrease in swelling and edema.

Hospital treatment ended 14 days after arrival at hospital, and the patient was discharged (Figure 4). Follow-up information obtained from the referring veterinarian 2 months post discharged, confirmed that the horse made a full and uneventful recovery.

\section{Discussion}

Preputial hematoma is subsequent to acute hemorrhage [3], generally caused by a trauma occur during breeding of a resistant mare, jumping over a fixed structure, or riding through tall brush. Swelling of the prepuce occurs within minutes and may prevent retraction of the penis into the preputial cavity resulting in paraphimosis [2]

With penile or preputial injury, edema develops in the loose connective tissue between the penis and internal lamina of the prepuce and the weight of edema causes muscular fatigue, followed by protrusion of the glans penis and internal preputial lamina from the preputial cavity [2]. Prolonged exposure may result in paraphimosis, an inability to retract the protruded penis into the prepuce. As edema increases, particularly at the preputial ring, a constricting cuff may form, further impairing venous and lymphatic drainage. It is clear that this course of 
events is self-perpetuating and accumulation of edema may render the penile and preputial epithelium fragile and easily damaged $[4,8]$.

Paraphimosis describes prolapse of the penis and internal laminae of the prepuce accompanied by inability to retract the penis into the preputial cavity [9]. Paraphimosis may be seen in geldings, although it is much more commonly seen in stallions $[9,10]$.

Paraphimosis may be a manifestation of disease characterized by extensive edema, such as preputial hematoma.

Other causes of paraphimosis are genital trauma, such as preputial laceration, penile hematoma, castration, dourine and purpura hemorrhagic [11-13] or it may be caused by damage to penile innervations. Penile denervation has been associated with spinal disease, trauma, and infectious diseases, such as equine herpes virus I and rabies [12,14]. Paralysis associated with priapism and debilitation has been reported $[15,16]$. Penile paralysis has followed administration of phenothiazine-derivative tranquilizers, most notably propiomazine (formerly termed propiopromazine) $[2,17,18]$. Paraphimosis can also be a sequel of priapism (persistent erection) or penile paralysis $[8,19,20]$.

Physical impediments, such as neoplastic masses, local edema secondary to castration, or cutaneous habronemiasis, may also prevent mechanical retraction of the penis into the prepuce [8-10]. Direct preputial hernia associated with an acquired ventral abdominal wall defect was reported [4]. All those conditions should be considered for differential diagnosis.

Ultrasonography may be performed to identify seromas, hematomas [8], abscesses [7] or direct preputial hernia [4], also can be used to assess the physical status of cavernous tissue and to identify urethral lesions, such as calculi or stenosing scars [2].

The ultrasonography at the clinical examination allows differentiating conditions to select the appropriate treatment. Regardless of the cause, prolonged protrusion of the penis and prepuce will be followed by increased blood flow to irritated or injured tissues, increased permeability of local blood vessels, and fluid extravasation into interstitial tissues [10]. Trauma may also be accompanied by hemorrhage from the venous plexus external to the thick connective tissue of the Tunica albuginea [1]. Edema and hemorrhage limit venous and lymphatic drainage, which leads to further swelling. Because the preputial ring at the junction between the penis and the internal laminae of the prepuce is fairly rigid, a cuff of edema usually forms distal to this site, resulting in more swelling and mechanical prevention of penis retraction. The greater the amount of time that the penis is prolapsed, the more the tissue is susceptible to additional trauma, induration, ischemia, and necrosis. If trauma and tissue swelling are severe, the urethra may become obstructed, which may cause rupture of the urethra or bladder [8].

Medical treatment should be directed at decreasing inflammation and dependent edema to facilitate reduction-retraction of the penis into the preputial cavity $[9,11]$. Treatment should also be directed at the underlying cause of the paraphimosis, if known. Ultrasonography allows to determinate preputial hematoma immediately to select the correct treatment. Local anti-inflammatory treatments include gentle hydrotherapy and massage. Systemic administration of antiinflammatories and diuretics may be used, but they are contraindicated for horses with an impaired ability to urinate.

In one study, inflammatory edema of the prepuce was induced in geldings. Injectable trichlormethiazide $(5 \mathrm{mg})$ and betamethasone $(0.25$ $\mathrm{mg}$ ) were administered $/ 45 \mathrm{~kg}$ (100 lbs.) of body weight. Comparisons were made with placebo, betamethasone and trichlormethiazide granules and furosemide treated horses. Both trichlormethiazide/ betamethasone products were significantly more effective than furosemide or the placebo [21].

Clinicians may be required to drain pockets of excessive fluid accumulation (seromas or hematomas) identified during ultrasonography to allow for reduction-retraction of the penis and prepuce into the preputial cavity [11]. Horses with chronic paraphimosis accompanied by penile paralysis or generalized preputial fibrosis are unlikely to regain the ability to retract the penis. Stallions with penile paralysis generally retain their libido but are unable to achieve erection $[12,17]$.

If voluntary control over extension and retraction of the penis does not improve with sustained replacement of the penis within the prepuce, or if reduction-retraction cannot be achieved with medical management, then surgical intervention should be pursued [22].

Surgical options for paraphimosis include partial posthectomy (reefing procedure), perineal urethrotomy, phallopexy (Bolz technique), or phallectomy (penile amputation) $[1,10,22]$. The choice of a surgical procedure depends on the nature and extent of tissue damage as well as the patient future intended use for breeding. These techniques have been described in detail elsewhere $[1,8,10,22]$.

A repulsion device was very effective in resolving the paraphimosis [6]. In this case, this type of methods had not been used, but could be challenge selecting in which cases is extremely necessary. It was reported the use of repulsion device with a direct preputial hernia and is it was contraindicated [4].

In conclusion the use of the ultrasonography is a helpful for a quick and accurate diagnosis for preputial hematoma. A successful treatment is totally related to reduce edema. Success is related with the prompt treatment.

\section{Acknowledgements}

The authors specially thank to Louisianne Drumond, Maria Fernanda Ortiz de Elguea, Mariana Devoto, Merecedes Lopez, Natalia Pallarols and Raul Lamuraglia for their constant support and contributions.

None of the contributing authors have received grants or speaker fees from commercial body within the past two years. The authors have declared no competing interest.

\section{Source of Funding}

"Institutional". This study was supported by Centro de rehabilitación y Hospital equino Kawell, Solis, Buenos Aires, Argentina

\section{References}

1. Schumacher J, Vaughan JT (1988) Surgery of the penis and prepuce. Vet Clin North Am Equine Pract 4: 473-491.

2. Schumacher J (2006) Penis and prepuce. In: Equine surgery. Auer J, Stick J (Eds). 3rd edn. Missouri: Saunders Elsevier.

3. Memon MA, McClure JJ, Usenik EA (1987) Preputial hematoma in a stallion. J Am Vet Med Assoc 191: 563-564.

4. O'Brien T, Koch C, Livesey M, Brounts S (2010) Direct preputial hernia associated with a ventral abdominal wall defect in a two-year-old gelding Equine Vet Educ 22: 321-325

5. Edwards JF (2008) Pathologic conditions of the stallion reproductive tract. Anim Reprod Sci 107: 197-207.

6. Koch C, O'Brien T, Livesey M (2009) How to construct and apply a penile repulsion device (Probang) to manage paraphimosis. American Association of Equine Practitioners. 
Citation: Funcia JP, Goñi JI, Guglielminetti A (2016) Preputial Hematoma in a 2 Years Old Horse. J Vet Sci Technol 7: 338. doi:10.4172/21577579.1000338

7. Hayden SS (2012) Treating equine paraphimosis. Compend Contin Educ Vet 34: E5.

8. Beltaire KA, Tanco VM, Bedford-Guaus SJ (2011) Theriogenology question of the month. Trauma-induced paraphimosis. J Am Vet Med Assoc 238: 161-164.

9. Clem M, DeBowes R (1989) Paraphimosis in horses-part I. Compend Contin Educ Pract Vet.

10. Varner D, Schumacher J (1999) Diseases of the penis. In: Equine medicine and surgery. Colahan P, Mayhew I, Merritt A, et al. (Eds). St. Louis: Mosby Inc., USA.

11. Brinsko S, Blanchard T, Varner D (2007) How to treat paraphimosis. In Proceedings. 53rd Annu Conv Am Assoc Equine Pract.

12. Neely DP (1980) Physical examination and genital diseases of the stallion. In: Current Therapy in Theriogenology. Morrow D (Eds). Philadelphia: WB Saunders.

13. Henning M (1956) Animal Diseases in South Africa. 3rd Edn. Pretoria, South Africa: Central News Agency Ltd.

14. Walker DF, Vaughan JT (1980) Surgery of the penis. In: Bovine and Equine Urogenital Surgery. Walker D, Vaughan J (Eds). Philadelphia: Lea \& Febiger, USA.
15. Simmons HA, Cox JE, Edwards GB, Neal PA, Urquhart KA (1985) Paraphimosis in seven debilitated horses. Vet $\operatorname{Rec} 116: 126-127$.

16. Schumacher J, Hardin DK (1987) Surgical treatment of priapism in a stallion. Vet Surg 16: 193-196.

17. Wheat JD (1966) Penile paralysis in stallions given propiopromazine. J Am Vet Med Assoc 148: 405-406.

18. Bolz W (1970) The prophylaxis and therapy of prolapse and paralysis of the penis occurring in the horse after the administration of neuroleptics. Vet Med Rev Leverkusen 4: 255-263.

19. Brinsko SP, Blanchard TL, Varner DD (2011) Surgery of the stallion reproductive tract. In: Manual of Equine Reproduction. 3rd edn. Maryland Heights, MO: Mosby Elsevier, USA.

20. Schumacher J, Varner D (2007) Surgical correction of abnormalities affecting the reproductive organs of stallions. In: Current Therapy in Large Animal Theriogenology. Youngquist RS, Threlfall WR (Eds). $2^{\text {nd }}$ edn. St Louis, MO: Saunders Elsevier, USA.

21. http://www.drugs.com/vet/naquasone-injectable-solution-can.html

22. Clem M, DeBowes R (1989) Paraphimosis in horses - Part II. Compend Contin Educ Pract Vet 11: 184-187. 